\title{
Persepsi dan Sikap Penyuluh Pertanian Kabupaten Gunungkidul terhadap Aplikasi Sistem Informasi Katam Terpadu
}

\author{
Rahima Kaliky ${ }^{1 *}$, Supardi ${ }^{2}$, Nur Hidayat ${ }^{1}$ \\ ${ }^{1}$ Balai Pengkajian Teknologi Pertanian-Badan Litbang Pertanian Yogyakarta \\ ${ }^{2}$ Dinas Pertanian dan Pangan Kabupaten Gunungkidul \\ *Corresponding author: rahimanonkaliky@yahoo.co.id
}

\begin{abstract}
Abstrak
Sektor pertanian masih diandalkan sebagai kontributor penting Produk Domestik Regional Bruto Daerah Istimewa Yogyakarta, padi merupakan komoditas pertanian penting, namun produksinya cenederung melandai. Perubahan iklim ekstrim menjadi salah satu factor penyebab kegagalan panen. Badan Litbang Pertanian telah menyediakan aplikasi Sistem Informasi Kalender Tanam Terpadu yang dapat memberikan informasi spasial dan tabular tentang teknologi budidaya tanaman padi berdasarkan prediksi variabilitas dan perubahan iklim pada level kecamatan. Penyuluh pertanian diharapkan menggunakan aplikasi tersebut untuk akses informasi teknologi budidaya padi, informasi iklim dan OPT kemudian meneruskannya kepada petani. Penelitian ini bertujuan untuk mengetahui persepsi, sikap, dan minat penyuluh di Kabupaten Gunungkidul terhadap aplikasi sistem informasi tersebut. Penelitian dilakukan dengan metode survey pada bulan September 2020 dan pengambilan sampel menggunakan metode acak sederhana, jumlah sampel 46 orang. Analisis data menggunakan statistic deskriptif dan disajikan dalam bentuk tabel dan grafik. Hasil penelitian menunjukan bahwa mayoritas penyuluh pertanian di Kabupaten Gunungkidul memiliki persepsi positif $(60,88 \%)$ terhadap manfaat aplikasi tersebut dan sebanyak 66,85\% memiliki persepsi positif terhadap kemudahan penggunaannya. Sebagian besar penyuluh memiliki sikap postifif ( $>60 \%)$, dan $65,2 \%$ penyuluh berniat untuk menggunakan aplikasi tersebut secara berkelanjutan dalam mendukung peningkatan produksi dan produktivitas padi di Kabupaten Gunungkidul.
\end{abstract}

Kata kunci: Si Katam Terpadu, Persepsi, Sikap, Minat, Penyuluh pertanian

\section{Abstract}

The agricultural sector is still considered as an important contributor to the Gross Regional Domestic Product of Gunungkidul Regency, rice is an important agricultural commodity, its production shows a tendency to increase. Extreme climate change and pest attack are two of the factors that need to be considered to avoid crop failure. The IAARD has provided the Application of Integrated Cropping Calendar Information System (ICCIS) which can provide spatial and tabular information about rice cultivation technology based on predictions of climate variability and change at the sub-district level. Agricultural extension agents are expected to use the application to access information on rice cultivation technology, climate information and pest and information then pass it on to farmers. This study aims to determine the perceptions, attitudes, and intention of extensionwork in Gunungkidul Regency towards ICCIS. The research was conducted with a survey method in September 2020 and the sampling used a simple random method, the number of samples was 46 people. Data analysis used descriptive statistics and presented in tables and graphs. The results showed that the agricultural extension workers in Gunungkidul Regency had a positive perception (60.88\%) of the usefulness of the ICCIS and $66.85 \%$ had a positive perception of the use of the application. Most of the extension workers had a positive attitude (> 60\%), and $65.2 \%$ of the extension workers had the intention to use the the ICCIS sustainably in supporting increased rice production and productivity in Gunungkidul Regency.

Keywords: ICCIS, Perceptions, Attitudes, Interests, Extensionwork 
Prosiding Seminar Nasional Pembangunan dan Pendidikan Vokasi Pertanian

Politeknik Pembangunan Pertanian Manokwari, 14 November 2020

e ISSN : 2774-1982

\section{PENDAHULUAN}

Sektor pertanian di Kabupaten Gunungkidul masih diandalkan sebagai kontributur utama terhadap produk domestic regional bruto (PDRB). Data series 2014-2019 BPS Kabupaten Gunungkidul menunjukkan kontribusi sector pertanian, kehutanan dan perikanan terhadap PDRB atas dasar harga berlaku pada tahun 2018 mencapai 24,214\%, dan berdasar harga konstan di tahun yang sama mencapai 21,102\%. Penelitian Hafni et al., (2017) menunjukkan bahwa sektor pertanian di Kabupaten Gunungkidul merupakan sektor unggulan dengan rata-rata nilai Location Quotient (LQ) sebesar 2,43 dan nilai Dymanic Location Quotient (DLQ) sebesar 1,26, dan subsektor tanaman pangan memberikan kontribusi terbesar yaitu 12,4 persen terhadap nilai PDRB. Produktivitas padi di Kabupaten Gunungkidul menunjukan kecenderingan yang meningkat dimana pada tahun 2011produktivitas padi sawah adalah 5,86 ton/ha meningkat menjadi 6,3 ton/ha ditahun 2015 begitu pula dengan padi lading, pada tahun 2011 produktivitasnya mencapai 4,46 ton/ha dan padatahun 2015 mencapai 4,64 ton/ha (BPS DIY, 2016).

Upaya peningkatan produksi tanaman pangan terutama padi terus diupayakan oleh Dinas Pertanian Kabupaten Gunungkidul, Balai Pengkajian Teknologi Pertanian Yogyakarta, serta stakeholders lainnya termasuk para petani dan penyuluh pertanian setempat. Upaya-upaya yang dilakukan untuk menigkatkan produksi tanaman pangan diantaranya diseminasi teknologi budidaya padi spesifik lokasi, upaya mengantisipasi factor penyebab gagal panen seperti perubahan iklim ekstrim yang menyebabkan keketringan/kebanjiran, dan serangan organisme pengganggu tanaman (OPT).

Upaya-upaya yang perlu dilakukan untuk mengurangi dampak perubahan iklim, yaitu identifikasi wilayah kekeringan, banjir, endemik hama dan penyakit serta memperbaiki sarana prasarana yang menunjang peningkatan produksi serta mengembangkan teknologi spesifik lokasi yang mampu meningkatkan produktivitas tanaman pangan (Santoso, 2016). Badan Litbang Pertanian telah menghasilkan aplikasi Sistem Informasi Kalender Tanam Terpadu (Si Katam Terpadu) sebagai pedoman atau alat bantu yang memberikan informasi spasial dan tabular tentang prediksi musim, awal tanam, pola tanam, luas tanam potensial, wilayah rawan banjir dan kekeringan, potensi serangan OPT, varietas padi dan kebutuhan benih, serta rekomendasi dosis dan kebutuhan pupuk berdasarkan prediksi variabilitas dan perubahan iklim pada level kecamatan untuk seluruh Indonesia. Alat bantu ini dapat diakses di website Badan Litbang Pertanian (http://katam.litbang.pertanian.go.id/) melalui personal computer atau smartphone (Anis et al., 2019). 
Prosiding Seminar Nasional Pembangunan dan Pendidikan Vokasi Pertanian Politeknik Pembangunan Pertanian Manokwari, 14 November 2020

e ISSN : 2774-1982

Aplikasi Si Katam Terpadu meupakan alat bantu yang sangat penting bagi penyuluh petanian untuk mengakses informasi-informasi tersebut untuk diteruskan kepada para petani di wilayah kerjanya (WKPP) dan memotivasi petani untuk mengaplikasikannya. Penguasaan berbagai aplikasi sistem informasi dalam bidang pertanian akan sangat menunjang kompetensi penyuluh pertanian. Penyuluh harus memiliki kompetensi sebelum melakukan penyuluhan, pendidikan maupun pelatihan bagi petani sehingga dapat memperkuat persepsi petani terhadap inovasi teknologi. Penyuluh yang berkinerja baik dapat memposisikan dirinya sebagai motivator, edukator, fasilitator dan dinamisator yang berdampak pada perubahan perilaku petani dalam berusahatani (Rahmawati et al., 2019).

Penelitian ini bertujuan untuk mengetahui persepsi, sikap, dan minat penyuluh penyuluh terhadap Si Katam Terpadu dalam mendukung peningkatan produksi dan produktivitas padi di kabupaten Gunungkidul.

\section{METODE}

Penelitian dilakukan dengan metode survey pada bulan September 2020. Metode survai, yaitu teknik kajian yang mengambil sampel dari suatu populasi dan menggunakan kuesioner terstruktur (Singarimbun dan Effendi, 2006). Populasi kajian ini adalah penyuluh pertanian perwakilan dari 17 BPP di Kabupaten Gunung Kidul. Pengambilan sampel dengan metode acak sederhana. Jumlah sampel sampel sebanyak 46 orang. Pengumpulan data dilakukan secara online menggunakan kuesioner google form untuk meminimalisir kegiatan kontak langsung ditengah pandemic covid 19. Analisis data menggunakan statistik deskriptif yang ditampilkan dalam bentuk tabel frekuensi dan persentase.

\section{HASIL DAN PEMBAHASAN}

\section{Karakteristik Responden}

Karakteristik individu penyuluh pertanian yang diamati meliputi umur, pendidikan, dan masa kerjanya seperti tersaji dalam Tabel 1.

Tabel 1. Karakteristik Penyuluh Pertanian di Kabupaten Gunung Kidul

\begin{tabular}{cccccc}
\hline $\begin{array}{c}\text { Usia } \\
(\text { Tahun) }\end{array}$ & $\begin{array}{c}\text { Persentase } \\
(\boldsymbol{\%})\end{array}$ & $\begin{array}{c}\text { Tingkat } \\
\text { Pendidikan }\end{array}$ & $\begin{array}{c}\text { Persentase } \\
(\boldsymbol{\%})\end{array}$ & $\begin{array}{c}\text { Masa Kerja } \\
(\text { Tahun) }\end{array}$ & $\begin{array}{c}\text { Persentase } \\
(\boldsymbol{\%})\end{array}$ \\
\hline $31-40$ & 32,6 & SMA & 17,4 & $1-10$ & 13 \\
$41-50$ & 13,0 & Diploma & 13,0 & $11-20$ & 41,3 \\
$51-60$ & 54,3 & S1 & 65,2 & $21-30$ & 13,0 \\
& & S2 & 4,3 & $31-40$ & 32,6 \\
\hline
\end{tabular}

Sumber: analisis data primer, 2020 
Prosiding Seminar Nasional Pembangunan dan Pendidikan Vokasi Pertanian

Politeknik Pembangunan Pertanian Manokwari, 14 November 2020

e ISSN : 2774-1982

Umur berkaitan dengan kemampuan seseorang dalam proses belajar mengajar dan pengalaman diri dan pada akhirnya akan mempengaruhi produktivitas kerja dan kemampuan dalam berpikir, bertindak dan mencoba (Nurfathiyah, 2019). Data pada Tabel 1 menunjukkan sebagian besar penyuluh pertanian di Kabupaten Gunungkidul hampir memasuki batas usia pensiun. Penyuluh pertanian ahli dengan jabatan penyuluh ahli madya batas usia pensiunnya adalah 60 tahun, sedangkan batas usia penyuluh ahli muda, ahli pertama dan penyuluh pertanian terampil adalah 58 tahun. Banyaknya jumlah penyuluh penyuluh yang akan memasuki usia pensiun dengan masa kerja pengabdian 31-40 tahun, perlu mendapat perhatian Pemda setempat dalam menyiapkan rekrutmen penyuluh baru di Kabupaten Gunungkidul mengingat penyuluh pertanian memiliki peranan penting dan strategia dalam menunjang pembangunan pertanian stempat.

Tingkat pendidikan penyuluh pertanian di Kabupaten Gunungkidul masuk dalam kategori tinggi dimana sebagian besar berpendidikan terakhir sarjana strata $1(65,2 \%)$, Diploma (13\%), dan S2 (4,3\%). tingginya tingkat pendidikan penyuluh pertanian setempat diharapkan dapat meningkatkan kualitas dan kemampuan dalam melaksanakan tugasnya.

\section{Aksesibilitas Penyuluh pada Aplikasi Si Katam Terpadu}

Informasi kalender tanam padi setiap kecamatan untuk seluruh Indonesia telah disusun sejak tahun 2007 oleh Badan Penelitian dan Pengembangan (Balitbang) Pertanian, Kementerian Pertanian dalam bentuk atlas. Pada perkembangannya, kalender tanam dinamik selanjutnya dilengkapi menjadi kalender tanam terpadu. Balitbang Pertanian terus memperbaharui informasi ini minimal tiga kali setahun pada setiap awal musim tanam dan dikemas dalam bentuk perangkat lunak yang berbasis website agar penyebaran informasi lebih cepat dan efisien ke seluruh Indonesia. Pengembangan sistem kalender tanam terpadu yang bersifat interaktif diharapkan dapat mempermudah pengambil kebijakan dan penyuluh pertanian dalam merekomendasikan awal waktu tanam serta kebutuhan benih/varietas dan pupuk pada setiap awal musim tanam (Runtunuwu et al., 2012)

Perkembangan teknologi informasi dan komunikasi telah memberikan banyak kemudahan dan menjelma menjadi media komunikasi pertanian yang potensial untuk dimanfaatkan oleh penyuluh untuk mendapat berbagai informasi pertanian dalam menunjang pekerjaannya. Sebanyak $89,1 \%$ penyuluh pertanian di Kabupaten Gunungkidul telah memiliki pengetahuan tentang Si Katam Terpadu, namun yang memanfaatkannya Si Katam Terpadu untuk mengakses berbagai informasi didalamnya baru mencapai 71,7\% penyuluh. Salah satu pertanyaan penelitian ini tentang kapan terakhir penyuluh mengakses Si Katam Terpadu? Jawaban atas pertanyaan ini terlihat dalam Tabel 2. 
Prosiding Seminar Nasional Pembangunan dan Pendidikan Vokasi Pertanian Politeknik Pembangunan Pertanian Manokwari, 14 November 2020

e ISSN : 2774-1982

Tabel 2. Periode Pemanfaatan Si Katam Terpadu oleh Penyuluh Pertanian

\begin{tabular}{cccc}
\hline No & Periode tahun & Jumlah & Persentase (\%) \\
\hline 1 & 2015 & 1 & 2,2 \\
2 & 2017 & 5 & 10,9 \\
3 & 2018 & 1 & 2,2 \\
4 & 2019 & 9 & 19,6 \\
5 & 2020 & 26 & 56,5 \\
\hline & Total & 42 & 91,4 \\
\hline
\end{tabular}

Sumber: Analisis data primer, 2020

Data pada Tabel 2 menunjukkan bahwa masih banyak penyuluh pertanian setempat yang belum memanfaatkan Si Katam Terpadu secara rutin. Pad tahun 2020 enyuluh yang menggunakan Si Katam Terpadu sebanyak 56,5 \%, sedangkan yang lainnya terakhir mengaksesnya pada tahun lalau, bahkan ada yang terakhir menggunakan Si Katam Terpadu pada 5 tahun lalu. Berdasar data ini, maka perlu dilakukan sosialisasi Si Katam Terpadu lagi kepada penyuluh pertanian sehingga mereka paham dan terampil dalam memanfaatkan Si Katam Terpadu untuk untuk mengakses berbagai informasi seperti kalender tanam, kondisi pertanaman (standing crop), teknologi pemupukan, alsitan dan varietas, bencana musiman dan endemic, dan informasi pendukung lainnya yang sangat diperlukan petani dalam memulai awal musim tanam.

Tabel 3. Menu Informasi yang di Akses oleh Penyuluh Pertanian

\begin{tabular}{clcc}
\hline No & \multicolumn{1}{c}{ Menu yang diakses } & Jumlah Responden & $\begin{array}{c}\text { Persentase } \\
(\mathrm{n}=60)(\%)\end{array}$ \\
\hline 1 & Kalender Tanam Terpadu & 33 & 55 \\
2 & Standing Crop & 4 & 6,67 \\
3 & Pemupukan & 27 & 45 \\
4 & Alsintan \& Varietas & 27 & 45 \\
5 & Bencana Musiman \& Endemik & 1 & 1,67 \\
6 & Monitoring & 2 & 3,33 \\
7 & Info Pendukung & 2 & 3,33 \\
\hline
\end{tabular}

Sumber: Analisis data primer, 2020

Berdasarkan tabel 3 menu informasi yang banyak diakses oleh penyuluh pertanian adalah informasi kalender tanam terpadu (55\%), pemupukan (45\%) serta alsintan dan varietas (45\%). Pada menu Katam terpadu penyuluh dapat memperolehinformasi mengenai kalender tanam level kabupaten dan kecamatan, data interaktif, grafik, validasi, dan katam rawa. Sedangkan untuk menu pupuk, alsintan, dan varietas akan memperoleh informasi mengenai rekomendasi pupuk, alsintan, dan varietas tanam yang tepat untuk digunakan. 
Prosiding Seminar Nasional Pembangunan dan Pendidikan Vokasi Pertanian Politeknik Pembangunan Pertanian Manokwari, 14 November 2020

e ISSN : 2774-1982

\section{Persepsi penyuluh terhadap Aplikasi Si Katam Terpadu}

Persepsi yang diamati adalah pandangan penyuluh mengenai kemanfaatan dan kemudahaan penggunaan Si Katam Terpadu. Persepsi merupakan proses interpretasi terhadap stimulus yang diterima oleh individu dan sangat tergantung pada penginderaanya. Rakhmat (2000) mengatakan persepsi merupakan pengalaman tentang objek, peristiwa atau hubungan-hubungan yang diperoleh dengan menyimpulkan informasi dan menafsirkan pesan. Dengan kata lain persepsi adalah pemberian makna pada stimuli indrawi, dan . pemaknaan tersebut melibatkan sensasi, atensi, ekspektasi, motivasi dan memori (Desiderato, 1976, cit Rakhmat, 2000). Sementara Iskandar dan Nurtilawati (2019) mengatakan persepsi dipengaruhi oleh interaksi sosial. Pandangan penyuluh terhadap manfaat dan kemudahn penggunaan aplikasi Si Katam Terpadu tersaji dalam Tabel 4.

Tabel 4. Persepsi Penyuluh terhadap manfaat aplikasi Si Katam Terpadu

\begin{tabular}{|c|c|c|c|c|c|c|}
\hline \multirow{2}{*}{ No } & \multirow{2}{*}{ Pernyataan } & \multicolumn{5}{|c|}{ Kategori (\%) } \\
\hline & & 1 & 2 & 3 & 4 & 5 \\
\hline & $\begin{array}{l}\text { Si Katam Terpadu bermanfaat bagi } \\
\text { penyuluh untuk mendapatkan } \\
\text { informasi: }\end{array}$ & & & & & \\
\hline 1 & $\begin{array}{l}\text { Rekomendasi } \\
\text { spesifik lokasi }\end{array}$ & 0 & 4,3 & 30,4 & 37 & 28,3 \\
\hline 2 & Rekomendasi varietas padi & 0 & 2,2 & 30,4 & 34,8 & 32,6 \\
\hline 3 & $\begin{array}{l}\text { Bencana kekeringan/banjir dan } \\
\text { endemkik di lahan sawah }\end{array}$ & 0 & 4,3 & 34,8 & 37 & 23,9 \\
\hline 4 & Waktu tanam yang tepat & 0 & 8,7 & 28,3 & 41,3 & 21,7 \\
\hline 5 & Pola tanam, rotasi tanaman & 2,2 & 8,7 & 39,1 & 26,1 & 23,9 \\
\hline 6 & Materi penyuluhan & 0 & 4,3 & 37 & 34,8 & 23,9 \\
\hline & Rerata & & 5,4 & 33,3 & 34,8 & 25,7 \\
\hline
\end{tabular}

Sumber: Analisis data primer, 2020

Keterangan: $1=$ Sangat tidak Setuju, $2=$ Tidak Setuju, $3=$ Ragu-ragu, $4=$ Setuju, $5=$ Sangat Setuju

Peresepsi kemanfaatan (perceived usefulness) merupakan suatu tingkatan dimana seseorang percaya bahwa pengguna suatu sistem tertentu akan meningkatkan prestasi kerja orang tersebut (Hanggono et al., 2015). Penyuluh yang punya pandangan positif (setuju dan sangat setuju) terhadap kemanfaatan Si Katam Terpadu dalam mendapatkan informasi tentang rekomendasi pemupukan, varietas, waktu tanam, bencana kekeringan/kebanjiran, pola dan rotasi tanam, dan materi penyuluhan mencapai $60,88 \%$ dan yang ragu-ragu mencapai $33,3 \%$, selebihnya memiliki persepsi negatif. Penyuluh yang masih ragu-ragu 
Prosiding Seminar Nasional Pembangunan dan Pendidikan Vokasi Pertanian Politeknik Pembangunan Pertanian Manokwari, 14 November 2020

e ISSN : 2774-1982

dan masih ada yang memiliki persepsi negative terhadap Si Katam Terpadu menandakan bahwa alat bantu ini belum terlalu popular di level mikro.

Tabel 5. Persepsi Penyuluh terhadap Kemudahan aplikasi Si Katam Terpadu

\begin{tabular}{|c|c|c|c|c|c|c|}
\hline \multirow{2}{*}{ No } & \multirow{2}{*}{ Pernyataan } & \multicolumn{5}{|c|}{ Kategori $(\%)$} \\
\hline & & 1 & 2 & 3 & 4 & 5 \\
\hline 1 & $\begin{array}{l}\text { Menu Aplikasi Si Katam Terpadu } \\
\text { mudah dipahami dan diaplikasikan }\end{array}$ & & & 50 & 34,8 & 15,2 \\
\hline 2 & $\begin{array}{l}\text { Informasi Si Katam Terpadu jelas dan } \\
\text { mudah dipahami }\end{array}$ & & & 39,1 & 45,7 & 15,2 \\
\hline 3 & $\begin{array}{l}\text { Aplikasi Si Katam Terpadu dapat di } \\
\text { akses kapan saja }\end{array}$ & & & 26,1 & 47,8 & 26,1 \\
\hline 4 & $\begin{array}{l}\text { Aplikasi Si Katam Terpadu mudah } \\
\text { diakses via smart phone maupun PC }\end{array}$ & & & 17,4 & 60,9 & 21,7 \\
\hline & Rerata & & & 33,15 & 47,3 & 19,55 \\
\hline
\end{tabular}

Sumber: Analisis data primer, 2020

Persepsi kemudahan penggunaan (perceived ease of use) adalah suatu tingkatan dimana seseorang mempercayai bahwa penggunaan system tertentu dapat mengurangi usaha seseorang dalam mengerjakan sesuatu (Hanggono et al., 2015). Tabel 5 menunjukkan bahwa sebanyak $66,85 \%$ penyuluh di Kabupaten Gunungkidul memiliki pandangan positif terhadap kemudahan penggunaan Aplikasi sistem informasi tersebut, sedangkan 33,15\% penyuluh lainnya masih ragu-ragu.

\section{Sikap (Attitude) Penyuluh terhadap Aplikasi Si Katam Terpadu}

Sikap merupakan cara pandang seseorang yang bersifat positif, negatif atau ambigu terhadap suatu objek sikap yang dapat mempengaruhi respon individu (Albarracin et al., 2005). Menurut Azwar (2007) sikap sebagai keteraturan tertentu dalam hal perasaan (afektif), pemikiran (kognitif), dan predisposisi tindakan (konatif) seseorang terhadap suatu objek (stimulus) di lingkungan sekitarnya. Sejalan dengan pemikiran petani dalam mengadopsi inovasi teknologi, penyuluh juga mempertimbangkan berbagai faktor sebelum mengubah sikap terhadap suatu teknologi. Menurut Hendayana (2016) secara normatif inovasi teknologi harus dirasakan sebagai kebutuhan, memberikan keuntungan, selaras dengan teknologi yang lama (inkulturasi), dapat mengatasi faktor-faktor pembatas, terjangkau kemampuan petani, tidak rumit, dan mudah diamati.

Sikap penyuluh dalam hal pemikiran/pemahaman (kognisi) perasaan (afektif), dan predisposisi tindakan terhadap Si Katam Terpadu terbaca dalam Tabel 6. 
Prosiding Seminar Nasional Pembangunan dan Pendidikan Vokasi Pertanian Politeknik Pembangunan Pertanian Manokwari, 14 November 2020

e ISSN : 2774-1982

Tabel 6. Sikap Penyuluh terhadap Aplikasi Si Katam Terpadu

\begin{tabular}{|c|c|c|c|c|c|c|}
\hline \multirow{2}{*}{ No } & \multirow{2}{*}{ Pernyataan } & \multicolumn{5}{|c|}{ Kategori } \\
\hline & & 1 & 2 & 3 & 4 & 5 \\
\hline 1 & $\begin{array}{l}\text { Merasa yakin bahwa dengan penggunaan } \\
\text { Aplikasi SI Katam Terpardu memudahkan } \\
\text { penyuluh dalam mengakses informasi } \\
\text { iklim dan rekomendasi tek budidaya padi } \\
\text { (kognisi) }\end{array}$ & & 6,5 & 30,4 & 43,5 & 19,6 \\
\hline 2 & $\begin{array}{l}\text { Aplikasi SI Katam Terpardu disukai } \\
\text { karena memudahkan penyuluh untuk } \\
\text { mengakses informasi iklim } \\
\text { rekomendasi teknlogi budidaya } \\
\text { (afeksi) }\end{array}$ & & 4,3 & 32,6 & 50 & 13 \\
\hline 3 & $\begin{array}{l}\text { Aplikasi SI Katam Terpardu akan } \\
\text { dimanfaatkan untuk mengakses informasi } \\
\text { iklim dan rekomendasi teknologi budidaya } \\
\text { padi secara cepat (konasi) }\end{array}$ & & 6,5 & 26,1 & 52,2 & 15,2 \\
\hline
\end{tabular}

Sumber: Analisis data primer, 2020

Tabel 6 menunjukkan bahwa mayoritas penyuluh sebagian besar penyuluh pertanian di Kabupaten Gunungkidul ( $>60 \%$ ) memiliki sikap yang positif terhadap aplikasi Si Katam Terpadu baik dari aspek kognisi, afeksi maupun konasi. Adanya sikap positif sebagian besar penyuluh tersebut juga terlihat minat/niat mereka untuk mengguakan sistem informasi tersebut (Behavioral intention to use). Behavioral intention to use merupakan kecenderungan perilaku untuk tetap menggunakan suatu teknologi (Davis, 1989) cit., Hanggono et al., 2015). Sebanyak 65,3\% penyuluh di Kabupaten Gunungkidul setuju bahwa akan menggunakan Aplikasi Si Katam Terpadu untuk akses informasi teknologi dan 65,2 \% setuju bahwa akan menggunakan Aplikasi Si Katam Terpadu secara berkelanjutan

\section{KESIMPULAN DAN SARAN}

Sebagian besar penyuluh pertanian pertanian di Kabupaten Gunung Kidul memiliki persepsi dan sikap yang positif terhadap aplikasi Si Katam Terpadu sebangai instrument yang memudahkan mereka dalam mengakses berbagai informasi yang menunjang dan menunjang upaya peningkatan produksi padi di Kabupaten serta memiliki minat/niat yang kuat (Behavioral intention to use) untuk mengunakan sistem informasi tersebut secara berkelanjutan. 
Prosiding Seminar Nasional Pembangunan dan Pendidikan Vokasi Pertanian

Politeknik Pembangunan Pertanian Manokwari, 14 November 2020

e ISSN : 2774-1982

\section{DAFTAR PUSTAKA}

Albarracin, B., T. Johnson, \& M.P. Zanna, M. (Eds.). (2005). The Handbook of attitudes. Lawrence Erlbaum Associates, London. pp. 173-222.

Anwas, E. Oss M. (2013). Pengaruh pendidikan formal, pelatihan, dan intensitas pertemuan terhadap kompetensi penyuluh pertanian. Jurnal Pendidikan dan Kebudayaan 19(1): 50-62.

Azwar. S. (2007). Sikap Manusia. Teori dan Pengukurannya. Penerbit Pustaka Pelajar, Yogyakarta.

BPS DIY. (2016). Provinsi DI Yogyakarta Dalam Angka. Badan Pusat Statistik Provinsi Daerah Istimewa Yogyakarta.

Hafni.N \& Amirulla Setya Hardi. (2017). Kontribusi sektor pertanian terhadap PDRB Kabupaten Gunungkidul tahun 2010-2014. Tesis S2 Ekonomika Pembangunan. Perpustakaan Universitas Gadjah Mada Yogyakarta http://etd.repository.ugm.ac.id/penelitian/detail/109672\#filepdf (akses, 07 Oktober 2020)

Fahri, A., Syuryati, A. Yulfida, \& R. Yusuf. (2019). Penerapan sistem informasi kalender tanam (SI KATAM) mendukung peningkatan indeks pertanaman padi di Kabupaten Indragiri Hulu. Jurnal Dinamika Pertanian 3: 1-8.

Hanggono, A. A>, S. R. Handayani, \& H. Susilo. (2015). Analisis atas praktek TAM (Technology Acceptance Model) dalam mendukung bisnis online dengan memanfaatkan jejaring sosial Instagram. Jurnal Administrasi Bisnis (JAB) 26(1): 1 9.

Hendayana. (2016). Persepsi dan Adopsi Teknologi. Landasan Teori dan Praktik Pengukuran. Penerbit IAARD, Bogor.

Iskandar, E., \& H. Nurtilawati. (2019). Persepsi petani dan penerapan teknologi pengelolaan tanaman terpadu di Desa SUkaresmi Kabupaten Bogor. Jurnal Agribisnis Terpadu 12(3) : 203-2016.

Nurfathiyah, P. (2019). Faktor-faktor yang mempengaruhi penyuluh pertanian dalam pemanfaatan media informasi di Kabupaten Batanghari. Jurnal Ilmiah Ilmu Terapan Universitas Jamb 3(1): 78-92.

Rakhmat, J. (2000). Psikologi Komunikasi. Remaja Rosdakarya. Bandung

Rahmawati, M. Baruwadi, \& M. I. Bahua. (2019). Peran kinerja penyuluh dan efektivitas pelaksanaan penyuluhan pada program intensifikasi jagung, JSEP 15(1): $56-70$.

Rahmawati, M. Baruwadi, \& M. I. Bahua. (2019). Peran kinerja penyuluh dan efektivitas pelaksanaan penyuluhan pada program intensifikasi jagung. JSEP 15 (1): 56-70.

Ruhimat, I. S. (2015). Tingkat motivasi petani dalam penerapan sistem agroforestry. Jurnal Penelitian Sosial dan Ekonomi Kehutanan 12(2): 1-11.

Runtunuwu, E., H. Syahbuddin, F. Ramadhani, A. Pramudia, D. Setyorini, K. Sari, Y. Apriyana, E. Susanti, Haryono, P. Setyanto, I. Las, \& M. Sarwani. (2012). Sistem informasi kalender tanam terpadu: status terkini dan tantangan kedepan. Jurnal Sumberdaya Lahan 6(2): 67-78.

Santoso, A. B. (2016). Pengaruh perubahan iklim terhadap produksi tanaman pangan di Provinsi Maluku. Penelitian Pertanian Tanaman Pangan 35(1): 29-38. 
Prosiding Seminar Nasional Pembangunan dan Pendidikan Vokasi Pertanian

Politeknik Pembangunan Pertanian Manokwari, 14 November 2020

e ISSN : 2774-1982

Singarimbun, M. \& Effendi S. (2006). Metode Penelitian Survai. LP3ES. Yogyakarta.

Tjiptoherijanto, P. (2001). Proyeksi Penduduk, Angkatan Kerja, Tenaga Kerja, dan Peran Serikat Pekerja dalam Peningkatan Kesejahteraan. Diakses melalui <https://www.bappenas.go.id/files/3513/5211/1083/prijono_20091015125259_2 356_0.pdf > Pada tanggal 24 September 2020. 